\title{
Road traffic injured patients with severe GCS and organ injury had a poor prognosis: a retrospective cohort study
}

\author{
Kissanet Tesfay ${ }^{1 *}$, Mulubirhan Assefa ${ }^{1}$, Dawit Zenebe ${ }^{1}$, Mekonnen Gebremicael ${ }^{2}$, Getahun Kebede ${ }^{2}$ and \\ Hayelom Gebrekirstos ${ }^{3}$
}

\begin{abstract}
Background: Ethiopia had an increasing trend of morbidity and mortality due to road traffic injury. Road traffic injured patient's recovery rate is affected by many different factors. Those factors might affect the duration of time to recovery. Therefore studying the median time to recovery and its predictors of road traffic injured patients will be needed to act upon the patient's hospital provided service.

Method: A retrospective cohort study design was employed. The study population was all admitted road traffic injured patients in Ayder tertiary hospital. We have used the total of all three-year RTI patients' chart from 2015 to 2017 found in the hospital. After excluding incomplete charts for major variables the sample size was 322. Descriptive statistics, life table, Kaplan-Meier, log-rank test and assumptions of the Cox proportional hazard model was applied. Bi and multivariate Cox regression analysis, hazard ratios and associated $95 \% \mathrm{Cl}$ were estimated.

Result: Male to female RTI patient ratio was 3:1. Of the total 258(80.1\%) had been recovered and the median survival time to recovery was 15 days (interquartile range 7-29). From those recovered, 104(40.3\%) had been referred from other health facilities. Availability of referral form linkage [adjusted hazard ratio $=1.5, \mathrm{Cl}(1.1-1.9)]$, mild and moderate glass coma scale [adjusted hazard ratio $=2.3, \mathrm{Cl}(1.3-3.9)$ ], conservative management [adjusted hazard ratio $=1.6, \mathrm{Cl}(1.2-2.1)$ ], and not having organ injury [adjusted hazard ratio $=1.6, \mathrm{Cl}(1.1-2.3)$ ] were associated with time to recovery in multivariate analysis.

Conclusion: Median time to recovery of road traffic injured patients was relatively good. Being referred from another health facility, mild and moderate glass coma scale, conservative management and without organ injury was positively associated with time to recovery of road traffic injured patients. We would like to recommend for future prospective studies to determine the time to return to work of road traffic injured patients and quality of life after the injury.
\end{abstract}

Keywords: Road traffic injury, Glass coma scale, Ayder comprehensive specialized referral hospital

\section{Background}

One of the sustainable development goal (SDG) targets was to reduce $50 \%$ of global road traffic collision deaths and injuries by 2020 [1]. However different studies conducted in Ethiopia showed that the trend of morbidity and mortality of road traffic injury (RTI) in the country had been increasing from

\footnotetext{
*Correspondence: tesfaykissanet@gmail.com

${ }^{1}$ Department of Epidemiology, Mekelle University College of Health Science School of Public Health, Mekelle, Ethiopia

Full list of author information is available at the end of the article
}

year to year [2, 3]. According to, 2013 WHO's Global Status Report on Road Safety, Ethiopia had 68.3 deaths of RTI per 10,000 vehicles.

People with low socioeconomic status, males and young age groups were at high risk of road traffic injury [4]. Road traffic injured patient's recovery rate is affected by many different factors. Different studies have identified factors such as socio-demographic factors, crash characteristics, type of pre-hospital care given, hospital arrival mechanism, injury characteristics, and hospitalization care. Among those factors

(c) The Author(s). 2019 Open Access This article is distributed under the terms of the Creative Commons Attribution 4.0 International License (http://creativecommons.org/licenses/by/4.0/), which permits unrestricted use, distribution, and reproduction in any medium, provided you give appropriate credit to the original author(s) and the source, provide a link to the Creative Commons license, and indicate if changes were made. The Creative Commons Public Domain Dedication waiver (http://creativecommons.org/publicdomain/zero/1.0/) applies to the data made available in this article, unless otherwise stated. 
sex, age, glass coma scale (GCS) score, injury severity score (ISS) and systolic blood pressures at admission were increasingly associated with recovery from road traffic injured patients [5-10].

However, in Ethiopia as well in Ayder Comprehensive Specialized Referral Hospital little is known about epidemiological studies conducted on time to recovery and its predictor factors of road traffic injured patients. Therefore it is important that survival study is conducted to determine the time to recovery and its predictor factors among admitted road traffic injured patients.

\section{Methods}

\section{Study area and period}

The study was conducted in Ayder Comprehensive Specialized Referral Hospital from 2015 to 2017. Data was collected from March 1 to 30, 2018. The hospital is found in northern Ethiopia located $778 \mathrm{~km}$ from Addis Ababa. The hospital had 513 inpatient beds with three intensive care units.

\section{Study design}

Hospital-based retrospective cohort study design on RTI patient's record was conducted.

\section{Population}

\section{Source population}

All admitted road traffic injured patients in Ayder Comprehensive Specialized Referral Hospital from 1 January 2015 to 30 December 2017.

\section{Study population}

All road traffic injured patients from 1 January 2015 to 30 December 2017 admitted at Ayder Comprehensive Specialized Referral Hospital.

\section{Study unit}

All road traffic injured patients chart in Ayder Comprehensive Specialized Referral Hospital from 1 January 2015 to 30 December 2017.

\section{Eligibility criteria}

All medical records of road traffic injured patients who were admitted to Ayder Comprehensive Specialized Referral Hospital from 2015 to 2017 were included. Whereas, incomplete patient chart (for major variables) and repeat patients on RTI during the study time were excluded.

\section{Sample size determination}

The sample size was calculated using the stpower Cox STATA software version 12 . The calculation was done based on the assumption that type I error of $5 \%$, power of $80 \%$ and a standard deviation of 0.5 . From a previous study conducted in Turkey, the overall probability of recovery from a traumatic brain injury was $50 \%$ and hazard ratio for glass coma scale (survivals vs. nonsurvivals) was 0.643 [11]. Glass coma scale is a most common predictor in most literature. The total sample size was 322 .

\section{Sampling procedure}

All three-year records of RTI patients chart found in Ayder Comprehensive Specialized Referral Hospital were included. The total of three-year RTI patients chart was 342. We excluded 20 charts due to incompleteness for major variables such as length of stay, sex, age, GCS.

\section{Data collection tool and procedures}

English version data extraction check-list was developed and adapted from different works of literature. Data were extracted from registers, patient's card, intensive care unit (ICU) and operation notes using a data extraction tool for the occurrence of the event. The event was recovery from RTI.

The checklist consists variables such as sociodemographic variables, availability of referral linkage, patient blood pressure at admission, information regarding the injury, previous history of medical illness, the location of the injury, type of injury (Injury severity score), length of hospital stays, ICU admission, organ injury and patient management. The data was collected by three nurses that had a Bachelor of Science degree.

\section{Study variables \\ Dependent}

Time to recovery from road traffic injury.

\section{Independent}

Socio-demographic factors include age, sex, and address.

Patients' factors include the availability of referral form linkage, duration of RTI, the situation of patients during RTA and previous history of medical illness.

Clinical factors of patients include consciousness status at admission, blood Pressure at admission, the location of the injury, GCS, KTS II, patient management, organ injury, ICU admission and length of hospital stays.

\section{Data quality control}

Three days training was given to data collectors on the data collection checklist and technique. A pretest was undertaken on the checklist in 5\% at Ayder Comprehensive Specialized Referral Hospital before the actual data collection started. Amendment was made on the checklist for clarity and consistency. Every day during the data collection process the 
Table 1 Socio-demographic characteristics of RTI victims admitted at ACSRH, Mekelle, Ethiopia, 2015-2018 ( $N=322)$

\begin{tabular}{llll}
\hline Socio-demographic characteristics & $\begin{array}{l}\text { Recovered } \\
(N=258)\end{array}$ & $\begin{array}{l}\text { Censored } \\
(N=64)\end{array}$ & $\begin{array}{l}\text { Total } \\
(N=322)\end{array}$ \\
\hline Age of patients & & & \\
$0-14$ & $38(14.7 \%)$ & $5(7.8 \%)$ & $43(13.3 \%)$ \\
$15-24$ & $64(24.8 \%)$ & $10(15.6 \%)$ & $74(23 \%)$ \\
$25-35$ & $84(32.6 \%)$ & $16(25 \%)$ & $100(31.1 \%)$ \\
$>36$ & $72(27.9 \%)$ & $33(51.6 \%)$ & $105(32.6 \%)$ \\
Sex of patients & & & \\
Male & $197(76.4 \%)$ & $49(76.6 \%)$ & $246(76.4 \%)$ \\
Female & $61(23.6 \%)$ & $15(23.4 \%)$ & $76(23.6 \%)$ \\
Residence of patients & & & \\
$\quad$ Urban & $111(43.0 \%)$ & $29(45.3 \%)$ & $140(43.5 \%)$ \\
Rural & $147(57 \%)$ & $35(54.7 \%)$ & $182(56.5 \%)$ \\
Ethnicity & & & \\
Tigrawi/ti & & & \\
Other ${ }^{a}$ & $234(90.7 \%)$ & $59(92.2 \%)$ & $293(91.0 \%)$ \\
\hline
\end{tabular}

Other ${ }^{\mathrm{a}}$ include Afar, Amhara, and Benshangul gumuz

checklist was checked for completeness, consistency, and accuracy by the principal investigator.

\section{Data processing and analysis}

The data was coded; entered, and cleaned using SPSS version 21. And assumptions were checked using STATA version 12 . The levels of missing values, the presence of influential outliers, multicollinearity, normality, and proportionality of hazards over time have

Table 2 Characteristics of the road traffic injured patients admitted to ACSRH: 2015-2017 ( $N=322)$

\begin{tabular}{|c|c|c|c|}
\hline Patient factors & Recovered $(N=258)$ & Censored $(N=64)$ & Total $(N=322)$ \\
\hline \multicolumn{4}{|c|}{ Availability of referral form linkage } \\
\hline Yes & $104(40.3 \%)$ & $15(23.4 \%)$ & $119(37 \%)$ \\
\hline No & 154(59.7\%) & $49(76.6 \%)$ & 203(63\%) \\
\hline \multicolumn{4}{|c|}{ Duration after RTC collusion } \\
\hline$<12$ Hours & 185(71.7\%) & $51(79.7 \%)$ & $236(73.3 \%)$ \\
\hline 12-24 Hours & $26(10.1 \%)$ & $2(3.1 \%)$ & $28(8.7 \%)$ \\
\hline$>24$ Hours & $47(18.2 \%)$ & $11(17.2 \%)$ & $58(18 \%)$ \\
\hline \multicolumn{4}{|c|}{ The situation of patients during RTA } \\
\hline Passengers & $119(46.1 \%)$ & 25(39.1\%) & $144(44.7 \%)$ \\
\hline Pedestrian & $90(34.9 \%)$ & $32(50.0 \%)$ & $122(37.9 \%)$ \\
\hline Driver & $46(17.8 \%)$ & $7(10.9 \%)$ & $53(16.5 \%)$ \\
\hline Other & $3(1.2 \%)$ & 0 & $3(0.9 \%)$ \\
\hline \multicolumn{4}{|c|}{ History of previous medical illness } \\
\hline Yes & $11(4.3 \%)$ & $7(10.9 \%)$ & $18(5.6 \%)$ \\
\hline No & $247(95.7 \%)$ & $57(89.1 \%)$ & $304(94.4 \%)$ \\
\hline
\end{tabular}

been checked. Proportionality of hazard over time was met and the mean-variance inflation factor was 1.86 .

Descriptive statistics, life table, Kaplan-Meier (KM) survival, and hazard functions were applied to estimate the probability of recovered patients from RTI and Logrank test was used to compare the KM curves for two or more categories of RTI patients.

The model for Cox proportional hazard is [12]

$$
h(t, X)=h 0(t) \exp \left[\sum \beta i x i\right]
$$

Where;

$h x(t)=$ hazard function

$\mathrm{h} 0(\mathrm{t})=$ baseline hazard

exp. $(\beta \mathrm{iXi})=$ function reflects how the hazard function changes according to difference in subjects' characteristics $(\mathrm{X})$

Cox proportional hazard model was used to determine the relationship between independent variables and the outcome variable (time to recovery from RTI). First bivariate Cox-regression analysis was done to estimate the crude hazard ratios (CHR). Every independent variable was tested against the dependent variable and variables significant at $P<0.25$ in bivariate analysis and those which were significant predictors in the most studies was taken to the multivariate Cox regression model. Then multivariate Coxregression analysis was performed to estimate the Adjusted Hazard Ratios (AHR). AHR with 95\% Confidence Interval (CI) was used to measure the association between dependent and independent variables.

\section{Operational definitions}

Event (1) was defined as the occurrence of recovery from road traffic injury.

Time to recovery was defined as time to occurrence of recovery from a road traffic accident.

Recovery was defined as when RTI patients' chart showed that the patient had improved with or without permanent disability and discharged.

Censored (0) was when a patient is transferred, discharge against medical advice, study time completion and died.

Glass coma scale was classified as severe (GCS 3-8), moderate (GCS 9-12) and mild (GCS 13-15) [5].

Kampala trauma severity Score II (KTS II) was classified as mild injury 9-10, moderate injury 7-8 and severe injury 6 or less $(\leq 6)[13]$.

Permanent disability includes light damage with minor neurological and psychological deficits or no need for assistance in everyday life; employment is possible but may require special equipment or permanent need for help with daily living [9].

Availability of referral form is defined as when a patient comes with a written referral form from referring health 
Table 3 Clinical factors of road traffic injured patients admitted at ACSRH, 2015-2017 ( $N=322)$

\begin{tabular}{|c|c|c|c|}
\hline Variables & Recovered $(N=258)$ & Censored $(N=64)$ & Total $(N=322)$ \\
\hline \multicolumn{4}{|c|}{ History of loss of consciousness at admission } \\
\hline Conscious & $137(53.1 \%)$ & $23(35.9 \%)$ & $160(49.7 \%)$ \\
\hline Unconscious & $121(46.9 \%)$ & $41(64.1 \%)$ & $162(50.3 \%)$ \\
\hline \multicolumn{4}{|l|}{ Admission blood pressure } \\
\hline$<90 / 60$ & $9(3.5 \%)$ & 10(15.6\%) & 19(5.9\%) \\
\hline $90 / 60-140 / 90$ & $246(95.3 \%)$ & $51(79.7 \%)$ & $297(92.2 \%)$ \\
\hline$>140 / 90$ & $3(1.2 \%)$ & $3(4.7 \%)$ & $6(1.9 \%)$ \\
\hline \multicolumn{4}{|l|}{ Injured body part } \\
\hline Extremities injury & $156(60.5 \%)$ & $15(23.4 \%)$ & $171(53.1 \%)$ \\
\hline Head injury & $110(42.6 \%)$ & $47(73.4 \%)$ & 157(48.8\%) \\
\hline Chest injury & $25(9.7 \%)$ & $8(12.5 \%)$ & $33(10.2 \%)$ \\
\hline Back injury & $10(3.8 \%)$ & $6(9.4 \%)$ & $16(4.9 \%)$ \\
\hline Other & $18(6.9 \%)$ & $5(7.8 \%)$ & $23(7.1 \%)$ \\
\hline \multicolumn{4}{|l|}{ Multiple Injury } \\
\hline Yes & $61(23.6 \%)$ & $17(26.6 \%)$ & $78(24.2 \%)$ \\
\hline No & 197(76.4\%) & $47(73.4 \%)$ & $244(75.8 \%)$ \\
\hline \multicolumn{4}{|l|}{ GCS at admission } \\
\hline Mild (13-15) and moderate (9-12) & $93(36.1 \%)$ & $17(26.6 \%)$ & $110(34.2 \%)$ \\
\hline Sever $(<=8)$ & $17(6.5 \%)$ & $30(46.8 \%)$ & $47(14.6 \%)$ \\
\hline NA & $148(57.4 \%)$ & $17(26.6 \%)$ & $165(51.2 \%)$ \\
\hline \multicolumn{4}{|l|}{ KTS ॥ } \\
\hline Moderate $(7,8)$ & 238(92.2\%) & $26(40.6 \%)$ & $264(82 \%)$ \\
\hline Severe $(\leq 6)$ & $20(7.8 \%)$ & $38(59.4 \%)$ & $58(18 \%)$ \\
\hline \multicolumn{4}{|l|}{ Type of patient management } \\
\hline Surgical & $155(60.1 \%)$ & $27(42.2 \%)$ & $182(56.5 \%)$ \\
\hline Conservative & 103(39.9\%) & $37(57.8 \%)$ & $140(43.5 \%)$ \\
\hline \multicolumn{4}{|l|}{ Admission to ICU } \\
\hline No & $227(88 \%)$ & $29(45.3 \%)$ & $256(79.5 \%)$ \\
\hline Yes & $31(12 \%)$ & $35(54.7 \%)$ & $66(20.5 \%)$ \\
\hline \multicolumn{4}{|l|}{ Organ Injury } \\
\hline No & $226(87.6 \%)$ & $15(23.4 \%)$ & $241(74.8 \%)$ \\
\hline Yes & $32(12.4 \%)$ & 49(76.6\%) & $81(25.2 \%)$ \\
\hline \multicolumn{4}{|l|}{ Length of Hospital Stay (LOS) } \\
\hline$<14$ Days & $136(52.7 \%)$ & $53(82.8 \%)$ & 189(58.7\%) \\
\hline 15 to 24 Days & 43(16.7\%) & $3(4.7 \%)$ & $46(14.3 \%)$ \\
\hline 25 to 34 Days & $33(12.8 \%)$ & $5(7.8 \%)$ & $38(11.8 \%)$ \\
\hline > 35 Days & $46(17.8 \%)$ & $3(4.7 \%)$ & 49(15.2\%) \\
\hline
\end{tabular}

facility attached with a patient chart or if there is a written history of being referred from another health facility.

\section{Result}

Socio-demographic factors

The overall recovery rate was $258(80.1 \%)$, and 64(19.9\%) was censored. From the 258 recovered road traffic injured patients $134(51.9 \%)$ of them had a permanent disability.

The mean and standard deviation of RTI patients' age was $30.1 \pm 15.9$. Male to female ratio of RTI victims was 3:1. Socio-demographic characteristics overall and stratified by recovery status are presented in Table 1. 


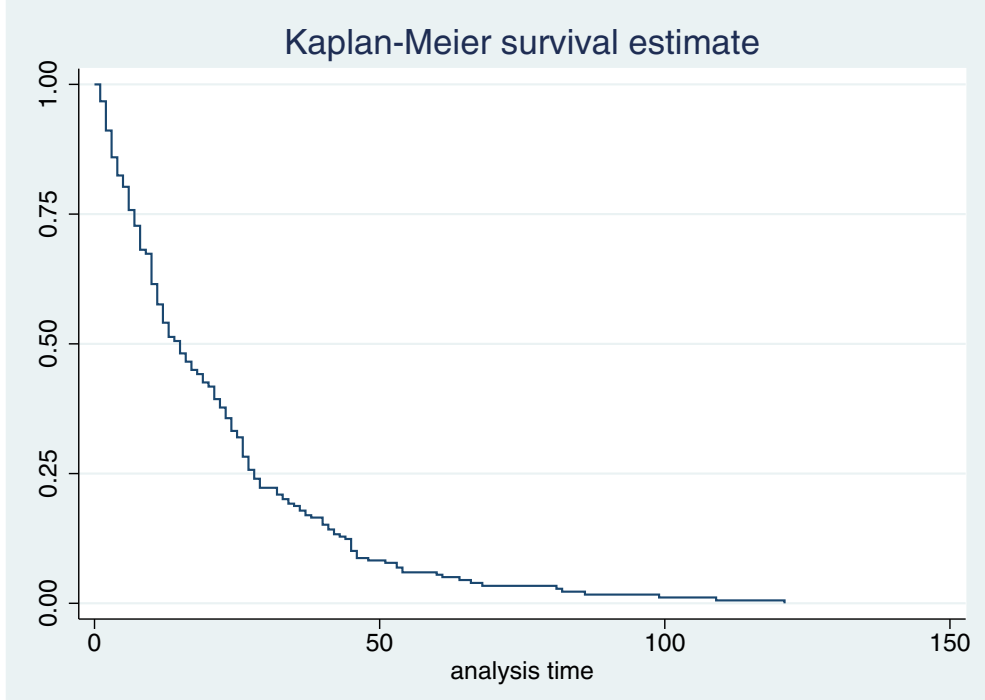

Fig. 1 Kaplan-Meier curve of time to recovery of RTI patients in ACSRH, 2015-2017

\section{Patient factors}

RTI patients with referral form were 104(40.3\%). Recovered patients arrived at the hospital within $12 \mathrm{~h}$ of the occurrence of the injury was $71.7 \%$. Passengers accounted for 144(44.7\%) (Table 2).

\section{Clinical factors}

RTI patients admitted into surgical ward 205(63.7\%), Orthopedics surgery ward 60(18.6\%), Pediatrics ward

Table 4 Log-rank test of time to recovery among covariates in ACSRH 2015-2017 ( $N=322)$

\begin{tabular}{llll}
\hline Variables & Chi-square & Degree of freedom & $P$-value \\
\hline Age & 2.93 & 3 & 0.40 \\
Sex & 1.79 & 1 & 0.18 \\
Place of residence & 1.72 & 1 & 0.19 \\
Availability of referral form & 7.96 & 1 & $0.005^{*}$ \\
Duration before hospital & 0.34 & 2 & 0.84 \\
arrival & & & \\
The situation of patients & 0.664 & 3 & 0.88 \\
during RTA & & & \\
Comorbidity & 3.16 & 1 & 0.08 \\
Consciousness status & 0.33 & 1 & 0.56 \\
Admission BP & 1.28 & 2 & 0.53 \\
Multiple injury & 0.96 & 1 & 0.33 \\
Admission GCS & 13.2 & 1 & $0.000^{*}$ \\
KTS II & 4.48 & 1 & $0.03^{*}$ \\
Management & 13.14 & 1 & $0.000^{*}$ \\
ICU admission & 5.6 & 1 & $0.018^{*}$ \\
Organ injury & 6.2 & 1 & $0.012^{*}$ \\
\hline
\end{tabular}

"for the $p$-value of $<0.05$
45(14\%), Neurosurgery ward 6(1.9\%) and Gynecology ward $1(0.3 \%)$.

Among the admitted RTIs 160(49.7\%) were conscious of admission. Extremity injury of admitted RTI patients accounted for $171(53.1 \%)$ (Table 3 ).

\section{The median time to recovery of admitted RTI patients}

A total of 322 patients were followed for three different year period which produced a total of 5387 person day observation. The incidence of recovery was 5 per 100 person-day observation.

The cumulative survival probability of admitted RTI patients was $90.8 \%$ (95\%CI, 86.9-93.5) at day three, 79.8\% (95\%CI, 74.7-83.9) at day six, 50\% (95\% CI, 44.1$56)$ at day fifteen and $41.5 \%(95 \% \mathrm{CI}, 35.5-47.4)$ at day twenty-one. The overall cumulative survival probability was $0.5 \%$ (95\% CI, 0.05-2.5).

The median time to recovery of admitted road traffic injured patients was 15 days (interquartile range (IQR) 7, 29) Fig. 1.

The log-rank test showed that there was a statistically significant difference in time to recovery of availability of referral form, ICU admission, admission GCS, organ injury, KTS II and patient management (Table 4).

\section{Assessment of model adequacy}

The proportional hazards model assumption is one very important assumption in the Cox model. The graphical and statistical method was used to assess the assumption. The Cox Proportional Hazard model assumption was checked by Cox-Snell residual plot. The plot showed 


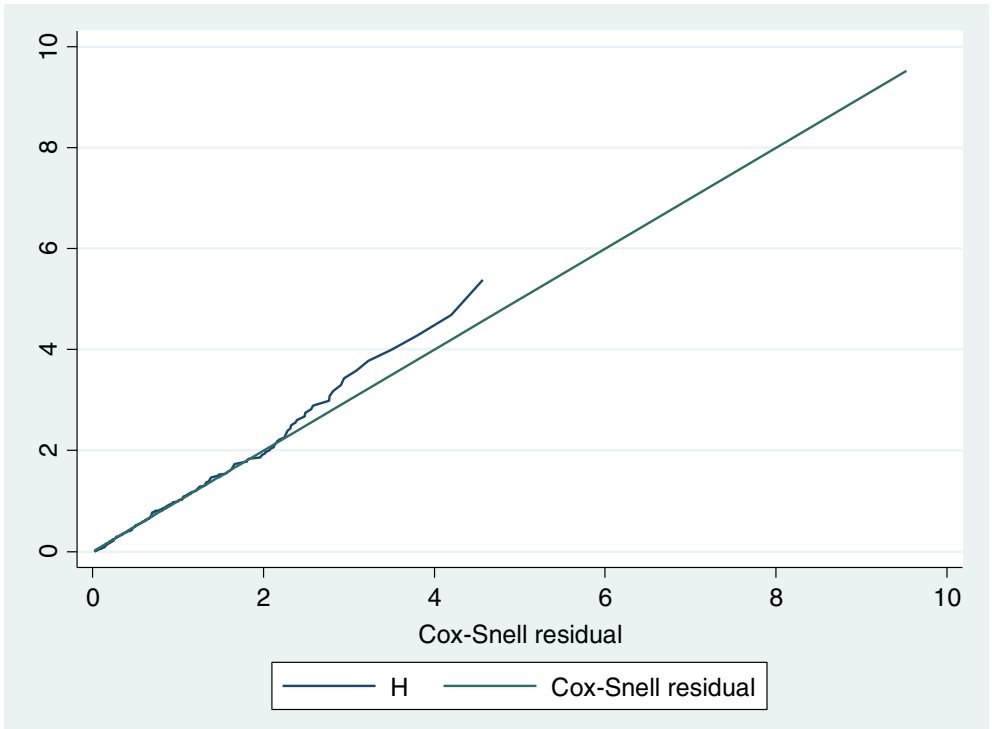

Fig. 2 Cox-Snell residual plot for checking the assumption of the model, on RTIs in ACSRH, 2015-2017

that the hazard follows the 45-degree line very closely and we conclude that the data was fitted well (Fig. 2).

Additionally, the Cox proportional hazard model assumption was checked by using Scaled Schoenfeld residual test (global test $P=0.76$ ) which indicated that the assumption was met.

\section{Predictors of time to recovery}

In Multivariate Cox $\mathrm{PH}$ model; availability of referral form 1.5(1.1-1.9), admission GCS 2.3(1.3-3.9), organ injury 1.6(1.1-2.3), and patient management 1.6(1.2-2.1) was significantly associated with recovery (Table 5).

\section{Discussion}

Our study result showed that median time to recovery was 15 days (IQR, 7-29) with $80.1 \%$ of overall recovery rate. Time to recovery was positively associated with having referral form, conservative management, not having organ injury, and mild and moderate admission GCS.

This study finding showed that the median time to recovery of RTI patients was 15 days (IQR, 7-29). This was in line with the median recovery time of studies done in Malawi (16 days), and South Africa (10 days) [14, 15]. However, our study finding differs from a study conducted in Kenya (30 days) [16]. The discrepancy might be due to that in Kenya there was a high number of extremity injured patients (56.4\%), while in this study it was $49.7 \%$ (95\% CI, 45-55.6\%). This could be due to the reason that extremity injury takes a long time to recover [17].

Though there is no standard to what constitutes adequate time to recovery for RTI patients our study identified a relatively good time to recovery compared with other studies conducted across Africa. But in our study, about $47 \%$ of severe GCS and $77 \%$ of organ injured RTI patients hadn't recovered which needs special attention.

In this study, the overall recovery rate of RTI patients was $80.1 \%$ (95\% CI, 75.2-84.5\%). This was in agreement with a cross-sectional study conducted in Tikur Anbesa of Ethiopia that had $77.5 \%$ of recovery rate [8]. And a retrospective cohort study of Tehran, Iran with $79.2 \%$ of RTI patient's recovery rate [9]. However our study finding was lower than cross-sectional studies done in Wolayta zone and Dire Dawa of Ethiopia, and Tanzania indicated that RTI patient's recovery rate was more than $90 \%[5,10,18]$. This disparity could be due to that in our study we included only admitted RTI patients whereas, in the studies done in Wolayta of Ethiopia, and Tanzania they had included all inpatient and outpatient trauma victims visited their hospital.

This study revealed that most of the recovered RTI patients $71.7 \%$ (95\% CI, 67.2-76.4) presented to the hospital within $12 \mathrm{~h}$ of the injury occurrence. This finding was higher than the study finding of Dire Dawa, Ethiopia which was $59.2 \%$ [10]. The difference could be due to the reason that Dire Dawa's RTI patient's arrival with the referral was $11 \%$ that was lower than compared to our study finding 37\% (95\% CI, 31.7-42.2). This might indicate for late patient hospital arrival in Dire Dawa study.

In this study, $52.7 \%(95 \% \mathrm{CI}, 47.7-58)$ of recovered RTI patients had less than 2 weeks of a length of hospital stay (LOS). This disagrees with study result of Dire Dawa, Ethiopia that had $19.4 \%$ of recovered RTI patients that had less than 2 weeks of LOS [10]. This might be 
Table 5 Cox Proportional Hazards Regression for time to recovery of RTIs in ACSRH, 2015-2017( $N=322)$

\begin{tabular}{|c|c|c|}
\hline Predictors & $\begin{array}{l}\text { Crude hazard ratio } \\
(95 \% \mathrm{Cl})\end{array}$ & $\begin{array}{l}\text { Adjusted hazard ratio } \\
(95 \% \mathrm{Cl})\end{array}$ \\
\hline \multicolumn{3}{|l|}{ Sex } \\
\hline Female & 1 & - \\
\hline Male & $0.82(0.61-1.10)^{*}$ & - \\
\hline \multicolumn{3}{|l|}{ Residence } \\
\hline Urban & 1 & - \\
\hline Rural & $0.835(0.65-1.07)^{*}$ & - \\
\hline \multicolumn{3}{|c|}{ Availability of referral form } \\
\hline No & 1 & 1 \\
\hline Yes & $1.43(1.06-1.84)^{*}$ & $1.5(1.13-1.91)$ \\
\hline \multicolumn{3}{|c|}{ History of previous medical illness } \\
\hline No & 1 & - \\
\hline Yes & $0.59(0.32-1.08)^{*}$ & - \\
\hline \multicolumn{3}{|l|}{ KTS ॥ } \\
\hline Sever & 1 & - \\
\hline Moderate & $1.63(1.02-2.61)^{*}$ & - \\
\hline \multicolumn{3}{|l|}{ Admission GCS } \\
\hline Severe & 1 & 1 \\
\hline $\begin{array}{l}\text { Mild and } \\
\text { moderate }\end{array}$ & $2.53(1.48-4.31)^{*}$ & $2.26(1.31-3.88)$ \\
\hline \multicolumn{3}{|l|}{ ICU admission } \\
\hline No & 1 & - \\
\hline Yes & $0.64(0.44-0.94)^{*}$ & - \\
\hline \multicolumn{3}{|c|}{ Patient management } \\
\hline Surgical & 1 & 1 \\
\hline Conservative & $1.59(1.2-2.06)^{*}$ & $1.6(1.19-2.13)$ \\
\hline \multicolumn{3}{|l|}{ Organ injury } \\
\hline Yes & 1 & 1 \\
\hline No & $1.58(1.09-2.29)^{*}$ & $1.6(1.09-2.31)$ \\
\hline
\end{tabular}

"variables with $p<0.25$

due to the difference in time of presence of RTI patients to the health facility.

This study revealed that RTI patients with available referral form were recovered more than those who came without referral form. This was in line with a study done in India [19]. This might be due to the reason that if patients come with referral paper, this could indicate they have got immediate access to first aid service and resuscitation in the nearby health facility. This could also indicate that referred patients might get special service regarding their referral reason.

The finding of our study showed that RTI patients with mild and moderate GCS score were more likely to recover than those with severe GCS score. This was in agreement with studies conducted in Kenya and Turkey $[11,16]$. This might be due to the reason that traumatic brain injured RTI patients who sustain a mild or moderate GCS have increased consciousness level and coordination than that of with severe GCS score. GCS is a quantifiable determination used for traumatic brain injured patients prognosis [17].

Our study finding of KTS II was not associated with RTI patient's recovery. However, this was not in line with the study result of Tanzania that showed severe KTS II was associated with unrecovered patients [5]. And also studies conducted in Kenya and Tehran of Iran showed increased injury severity score was associated with unrecovered patients $[9$, 16]. The difference with study in Tanzania could be due to the Tanzania study was prospective, whereas our study was retrospective. And the difference with studies of Kenya and Tehran of Iran could be due to that, they have used injury severity score (ISS) classification while we have used the Kampala injury severity score II (KTS II) classification.

In the present study, patients managed by conservative management were more likely to recover than those with surgical management. This is in agreement with studies conducted in Turkey and Dire Dawa of Ethiopia [10, 11]. This might be due to conservative management had no risk of surgical site infections which might not lead to prolonged hospital stay and complications.

Our study finding showed that RTI patients without organ injury were more likely to recover than those with organ injury. This was in line with a study conducted in Tehran of Iran [9]. The possible explanation could be due to organ damage causes fatal internal and external bleedings and organ failure which might lead to poor recovery and death.

The strength of this study was in an attempt done to conduct a study in time to recovery and its predictor factors among admitted RTI patients.

The limitation of the study was the data was secondary so important variables may be missed. The study lacks literature about time to recovery of RTI patients. There was no standard point of reference for time to recovery. And also the status and quality of life of RTI patients after discharge from hospital were not known.

\section{Conclusion}

Generally, the median time of recovery of admitted RTI patients was relatively high. Being referred from another health facility, conservative management, not having organ injury and mild and moderate admission GCS were found to be associated with better time to recovery of admitted RTI patients.

Ayder Comprehensive Specialized Referral Hospital should give attention to patients with the identified 
factors. Additionally, we would like to recommend for future prospective studies to determine the time to return to work of road traffic injured patients and quality of life after the injury.

\section{Abbreviations}

ACSRH: Ayder Comprehensive Specialized Referral Hospital; AHR: Adjusted Hazard Rate; CHR: Crude Hazard Rate; Cl: Confidence Interval; GCS: Glasgow Coma Scale; HR: Hazard Rate; ICU: Intensive Care Unit; IQR: Inter-Quartile Range; ISS: Injury Severity Score; KTS: Kampala Trauma Score; LOS: Length of Hospital Stay; RTI: Road Traffic Injuries; SBP: Systolic Blood Pressure;

SDG: Sustainable Development Goal; TBI: Traumatic Brain Injury; WHO: World Health Organization

\section{Publisher's Note}

Springer Nature remains neutral with regard to jurisdictional claims in published maps and institutional affiliations.

\section{Acknowledgments}

My deepest gratitude goes to Mekelle University, College of Health Science and the School of Public health and my family.

\section{Authors' contributions}

KTW contributed to the conception of the idea, draft writing, and statistical analysis. MAA and DZW contributed in editing the manuscript, reviewing and statistical analysis. HGM participated in proofreading and revising the draft manuscript. MGG and GKE had participated in statistical analysis and editing the manuscript. All authors have read and approved the manuscript.

\section{Funding}

None.

\section{Availability of data and materials}

The datasets used and/or analyzed during the current study are available from the corresponding author on reasonable request.

\section{Ethics approval and consent to participate}

Ethical clearance was obtained from an ethical review board of Mekelle University, College of Health Sciences and Department of Public Health. Informed consent from the study participants was waived by the Mekelle university ethical review board. Permission was obtained from Ayder Comprehensive Referral Hospital, Mekelle. The confidentiality of information regarding patients involved in this study was maintained by keeping all patients records within the study site and avoiding of identifying study participants by name on any documentation, report or publication resulting from data collected in this study.

\section{Consent for publication}

Not applicable.

\section{Competing interests}

The authors declare that they have no competing interests.

\section{Author details}

'Department of Epidemiology, Mekelle University College of Health Science School of Public Health, Mekelle, Ethiopia. ${ }^{2}$ Tigray Regional Health Bureau, Mekelle, Ethiopia. ${ }^{3}$ Adigrat University College of Health Science Department of Pharmacy, University of Saskatchewan, School of Public Health, Mekelle, Ethiopia.

Received: 12 March 2019 Accepted: 3 June 2019

Published online: 13 June 2019

\section{References}

1. WHO. Global status report on road safety. Geneva: World Health Organization; 2015.

2. Almaz Berhe AC, Bayray A. Assessment of Road traffic accidents among children in Addis Ababa City, Ethiopia; a retrospective record. Journal of Medical Science and Technology. 2014;3(3):25-36.
3. Asefa F, Assefa D, Tesfaye G. Magnitude of, trends in, and associated factors of road traffic collision in Central Ethiopia. BMC Public Health. 2014;14(1):1072.

4. WHO. Road traffic injuries, Fact sheet. Geneva: World Health Organization; 2018.

5. Chalya PL, Dass RM, Mchembe MD, Mbelenge N, Ngayomela IH, Chandika $A B$, et al. Citywide trauma experience in Mwanza, Tanzania: a need for urgent intervention. J Trauma Manag Outcomes. 2013;7(1):9.

6. Ghaffari-fam S, Sarbazi E, Daemi A, Sarbazi MR, Nikbakht HA, Salarilak S. The Epidemilogical characteristics of motorcyclists associated injuries in Road traffics accidents; a hospital-based study. Bull Emerg Trauma. 2016;4(4):223.

7. Solagberu BA, Balogun RA, Mustafa IA, Ibrahim NA, Oludara MA, Ajani AO, et al. Pedestrian injuries in the most densely populated city in Nigeria-an epidemic calling for control. Traffic Inj Prev. 2015;16(2):184-9.

8. Seid M, Azazh A, Enquselassie F, Yisma E. Injury characteristics and outcome of road traffic accident among victims at adult emergency Department of Tikur Anbessa specialized hospital, Addis Ababa, Ethiopia: a prospective hospital based study. BMC Emerg Med. 2015;15(1):10.

9. Hatamabadi HR, Shojaee M, Kashani P, Forouzanfar MM, Nargesi DA, Esfahani MRA. Predictive factors of poor outcome in road traffic injures; a retrospective cohort study. Emergency. 2017;5(1):1-8.

10. Negesa L, Mohammed J. Assessment of magnitude and treatment outcome of Road traffic accident from January 2013-January 2015 in Dilchora Referal hospital, Diredawa eastern Ethiopia. World J Surg Res. 2017;6(1):1-9.

11. Süt $N$, Memis $D$. Intensive care cost and survival analyses of traumatic brain injury. Ulus Travma Acil Cerrahi Derg. 2010;16(2):149-54.

12. Kleinbaum DG, Klein M. Survival analysis: a self-learning text. 3rd ed. USA: Springer; 2012.

13. Mutooro S, Mutakooha E, Kyamanywa P. A comparison of Kampala trauma score II with the new injury severity score in Mbarara University teaching hospital in Uganda. East Central Afr J Surg. 2010;15(1):62-71.

14. Sothmann JSJ, Kruger N, Dunn R. Epidemiology of acute spinal cord injuries in the Groote Schuur hospital acute spinal cord injury (GSH ASCI) unit, Cape Town, South Africa, over the past 11 years SAMJ. S Afr Med J. 2015;105(10):835-9.

15. Chagomerana MB, Tomlinson J, Young S, Hosseinipour MC, Banza L, Lee CN High morbidity and mortality after lower extremity injuries in Malawi: a prospective cohort study of 905 patients. Int J Surg. 2017;39:23-9.

16. Saidi $\mathrm{H}$, Mutiso BK, Ogengo J. Mortality after road traffic crashes in a system with limited trauma data capability. J Trauma Manag Outcomes. 2014;8(1):4.

17. Billiar T, Andersen D, Hunter J, Brunicardi F, Dunn D, Pollock RE. Schwartz's principles of surgery. Texas: McGraw-hill professional; 2004.

18. Hailemichael F, Suleiman M, Pauolos W. Magnitude and outcomes of road traffic accidents at hospitals in Wolaita zone, SNNPR, Ethiopia. BMC Res Notes. 2015;8(1):135.

19. Garwe T, Cowan LD, Neas B, Cathey T, Danford BC, Greenawalt P. Survival benefit of transfer to tertiary trauma centers for major trauma patients initially presenting to nontertiary trauma centers. Acad Emerg Med. 2010;17(11):1223-32.

\section{Ready to submit your research? Choose BMC and benefit from:}

- fast, convenient online submission

- thorough peer review by experienced researchers in your field

- rapid publication on acceptance

- support for research data, including large and complex data types

- gold Open Access which fosters wider collaboration and increased citations

- maximum visibility for your research: over $100 \mathrm{M}$ website views per year

At $\mathrm{BMC}$, research is always in progress.

Learn more biomedcentral.com/submissions 